\title{
Monitoring of the Results through a Survey Concerning the Socio-Economic Characteristics of the Elderly Using Geographic Information Systems (GIS): A Case Study in Greece
}

\author{
${ }^{1}$ Dermatis Zacharias, ${ }^{2}$ Anastasiou Athanasios \\ ${ }^{1} \mathrm{PhD}$, Department of Economic Studies, University of Peloponnese Greece, \\ ${ }^{2}$ Assistant Professor, Department of Management Science and Technology, University of \\ Peloponnese Greece
}

\begin{abstract}
The aim of the study is the determination of socio-economic characteristics of the elderly, emphasizing the usefulness of Geographic Information Systems (GIS) to explore the socio-economic indicators that affect the health level of the elderly. Given the usefulness of GIS and their application in the fields of physical health, mental health, health services and general health management, a survey for the investigation of the socio-economic indicators that affect the health level of the elderly was carried out, using a specially designed questionnaire. The results of this survey were plotted in the corresponding geographical locations on the maps, giving the person concerned a full picture of the geographical distribution of socio-economic indicators that affect the health level of the elderly.
\end{abstract}

Keywords: GIS, Socioeconomic factors, Elderly people, Quality of life, E-health

\section{Introduction}

Given the usefulness of Geographic Information Systems (GIS) and their application in the areas of physical health, mental health, health services and general health management, the results of the survey were mapped as graphs in the respective geographic locations on the maps, providing the person concerned with a full picture of the geographical distribution of economic and social characteristics and, above all, the health status of the elderly by region. Thus, the public institutions and health service providers concerned are given the opportunity to take prompt decisions on their actions.

The purpose of the case study is to investigate the socio-economic indicators that affect the health level of the elderly by using a specially designed questionnaire. The quantitative data method has been selected for the survey, which allows the systematic collection of objective numerical data and then its performance in numerical form for purposes of statistical analysis. More specifically, a specially designed questionnaire was used in print and in electronic form.

In order to obtain valid and scientific results, a representative sample of the studied population was collected, i.e. 897 questionnaires, so that the results and conclusions drawn from them and related to the particular population could be generalized. Methods of Descriptive Statistics (calculation of frequencies and frequency distributions, central trend indicators, dispersion) were applied in order to present the study data and to draw conclusions about the population under investigation. 
For the present study the quantitative approach is followed by the large population. The quantitative approach allows research to be conducted on a large part of the target population and "allows the researcher to learn what is happening but does not give interpretation to understand the experience". It also follows the principle of generalizing a conclusion from the specimen under study in a minor proportion of the population (Cohen \& Manion, 1994).

Section 2 describes the applications of Geographic Information Systems in Health and the correlations between the different socio-economic factors and the quality of health. Section 3 presents the case study and the methodology followed for its implementation, and the final Section presents the conclusions of the study.

\section{Literature Review}

\subsection{Applications of Geographical Information Systems in Health}

The use of GIS systems is widely applied to public health and many studies are based on them. Researchers today to address various health problems use modern GIS systems and other mapping applications on the computer. Forecasts as well as simulation models rely on these systems.

Public Health Informatics (PHI) is an emerging specialty, which focuses on the application of information technology and technology to the practice of Public Health and Research (Hanchette, 2003). As part of this effort, a GIS or, more generally, a Spatial Decision Support System (SDSS) offers improved geographic imaging techniques, resulting in faster and better decision making in the field of Public Health (Yasnoff \& Miller, 2003 ).

GIS techniques are used to show the lack of correlation between causes and effects or between different outcomes. GIS can contribute to Public Health in many ways because they can provide information on many issues and support the decision-making process properly. They can provide information on the distribution of health services.

Thus, any disparities that are increasing continuously could be abolished. Also, policy-makers can be helped and made the right decisions. Health professionals can easily identify the difficulties and inequalities in accessibility to health services and thus be able to cope with the current situation (Foley, 2002). For example, eliminating inequalities in health is one of the two primary goals of the Healthy People 2010 program currently in the US. The use of GIS can play an important role in this effort by helping Public Health professionals to identify the areas of weakness and inequality and helping them ideally to identify and develop solutions to address these deficiencies. GIS can also help researchers integrate dissimilar data from a wide range of sources, and can still be used to impose quality control measures on these data. The use of GIS has increased exponentially to solve various public health issues. These systems are critical to assessing and addressing relevant health problems in different areas of the earth (Foley, 2002).

A Geographic Information System can play an important role in the surveillance, management and analysis of diseases. It appears to be an important tool for the analysis and presentation of epidemiological data. Public health services, diseases, as well as any health information can be mapped and associated with various information such as environmental data, health and social data.

This creates a means of monitoring and managing disease and health programs. It is necessary to understand, monitor and emphasize the reasons that may be related to the development of a disease. Some of these factors could be the environment, behaviour and the socio-economic level of a region. If the "source" of the disease is recognizable and its 
development and transmission is known, health managers will be able to cope effectively with pandemics (Najafabadi, 2009; Ezatti et al., 2005). A GIS system is a tool with great potential that could contribute to assessing environmental risks and human exposure to them.

\subsection{Socio-Economic Factors}

There are many bibliographical references demonstrating the strong positive correlation between socio-economic status (SES) and health for many populations in many social sectors (Adler \& Ostrove, 1999; Feinstein 1993; Von dem Knesebecketal., 2006; Kitagawa \& Hauser 1973 Marmot, et al., 1997). Moreover, there is ample literature on the causal mechanisms of linking socio-economic dimensions and health. For example, education is considered to promote good health not only through the creation of financial resources (income and employment) but also through the provision of socio-psychological resources, ie healthy behaviors (Ross \& Wu, 1995; Mirowsky \& Ross, 1999), anxiety ability (Lantz et al., 2005; Lin \& Ensel, 1989), self-control (Mirowsky \& Ross, 1998; Taylor \& Seeman, 1999) to better manage disease and disease (Goldman \& Smith, 2002).

Income has been shown to promote health by influencing diet, quality of housing, exposure to environmental hazards, stress, and access to adequate health care (Cohen et al., 2003, Hayward et al., 1988; et al., 1994; House, 2002; Lantz et al., 2005). Individuals or families with low income are particularly vulnerable because they may not be able to have good physical and mental health (Andrulis 1998), restriction of access to healthy foods (Darmon et al., 2002; Caraher et al., 1998), resulting in toxic environments (Evans \& Katrowitz, 2002) and unhealthy housing conditions associated with a high risk of illness (Rosenbaum, 2008). Further research has shown that income is more closely linked to the evolution (rather than onset) of the disease than the level of education (Herd et al., 2007; Zimmer \& House, 2003), suggesting that the financial resources promote health in part by increasing the person's ability to pay for medical care and to transfer it to appropriate health care units. Many studies highlight the causal mechanisms by which the socio-economic situation affects people's health. According to Figure 4.3, the causal relationships between health and socio-economic status, in socio-political-economic conditions, to the extent that they facilitate or interfere with the mechanisms through which a person's socio-economic condition affects health (Link \& Phelan, 1995). Link and Phelan (1995) argue that social factors greatly affect health and hence the emergence of diseases with various mechanisms.

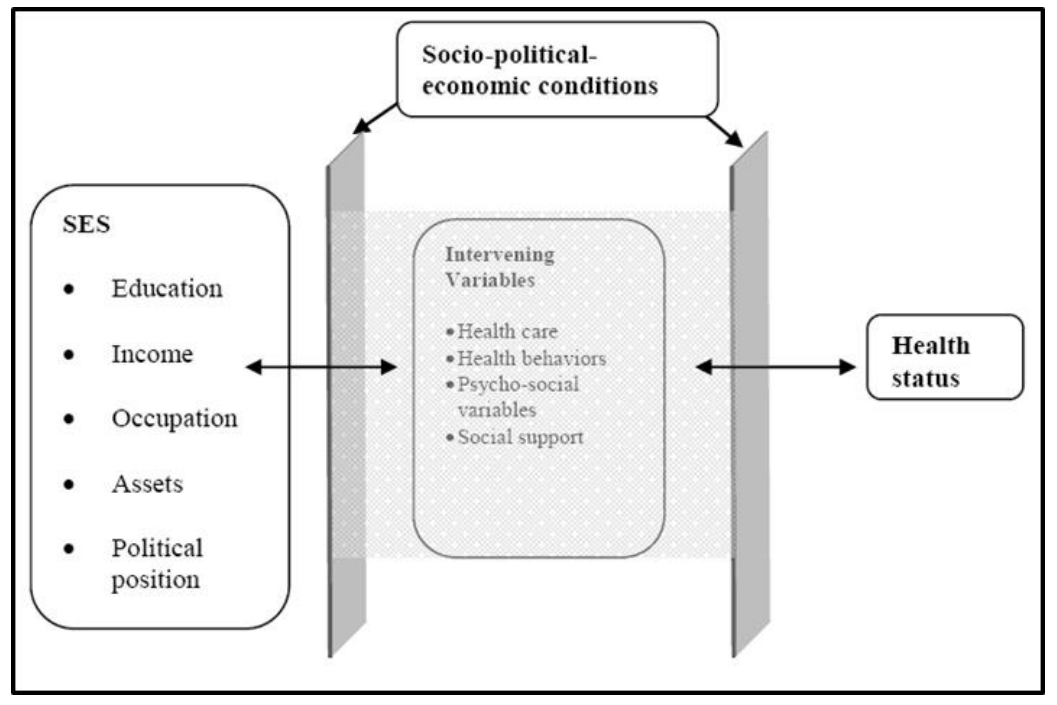

Figure 1: Socio-economic Factors and Health Source: Link \& Phelan, 1995 


\section{Case Study}

\subsection{Research Methodology}

The aim of the case-study is to investigate the socio-economic indicators that affect the health level of the elderly and their monitoring using Geographic Information Systems (GIS). The main objectives of the survey are to record the current elderly profile, explore the perception of the elderly about the impact of the economic crisis on their health status and lifestyle, assess the factors that shape the quality of life of the elderly, the degree of correlation of the socio-economic indicators with the quality of life of the elderly in research and the investigation of the differentiation of the degree of correlation of the socio-economic indicators with the quality of life of elderly.

Given the usefulness of Geographic Information Systems (GIS) and their application in the fields of physical health, mental health, health services and general health management, the results of the survey are plotted in the corresponding geographical locations on the maps, providing the person concerned with a complete picture of the geographical distribution of the socio-economic indicators that affect the level of health of the elderly per region. Thus, the public authorities and health service providers are given direct opportunity to take decisions on what they need to do.

For the collection of valid and scientific results, a representative sample of the studied population was collected (Belleli \& Papazoglou, 2004). In order to collect the data and to answer the research questions, questionnaires were distributed to the elderly of different KAPIs in Greece. A total of 897 questionnaires were completed so that the results and conclusions drawn from them and related to this population could be generalized.

To assess the relationship between the sense of quality of life and the socio-economic indicators that affect the health level of the elderly, we estimate the following model:We assume that $Y$ is a binary variable given from the following expression with is the Probit model with multiple regressors and $\Phi$ is the cumulative standard normal distribution function.

The predicted probability can be measured in two stages:

1.Calculate

2.Search for $\Phi(z)$ by considering pnorm( ). The coefficient $\beta j$ describes the impact on $z$ of a one unit change in $\mathrm{Xj}$ holding constant all other $\mathrm{k}-1$ regressors. Given the above specification, we can estimate the parameters using the method of maximum likelihood. The likelihood function is given by: Moreover, the dependent binary variable was created called Life Quality Sense (LQS), consisting of the Medium Term of Variable Quality of Life, Life Enjoyment, and Happiness Sense and takes the value 1 (Good Quality Life) if the Medium Term is greater or equal to 2 and the value 0 (Bad Quality Life) otherwise. As concerns the regressors, the variable AGE captures the Demographic Attribute taking values 1 (AGE< 70$), 2(70 \leq A G E \leq 80)$ and 3 (AGE $>80)$, the EDUC (values from $1(\mathrm{PhD})$ to 9 (None)) indicates Educational Level variable as a Social Attribute, the ECON (value 1 (Yes) and 2 (No)) and FIN (value 1

(income $>24.000,2(12.001 \leq$ income $\leq 24.000), \quad 3 \quad(6.001 \leq$ income $\leq 12.000), \quad 4$ $(1 \leq$ income $\leq 6.000)$ and 5 (income=0)) described Economic Autonomy and Annual Income respectively, are defined as Economic Characteristics, and finally variables PHYS (values 1 (totally agree) up to 5 (totally disagree)) and HEALTHY (values 1 (totally agree) up to 5 (totally disagree)) capture Physical Energy and Health Sense respectively as Health Characteristics.

Furthermore, the summary statistics for Quality of Life and Demographic, Social, Economic and Health Characteristics are listed in Table 1. 
Dermatis Zacharias, Anastasiou Athanasios

Monitoring of the Results through a Survey Concerning the Socio-Economic Characteristics of the Elderly Using Geographic Information Systems (GIS): A Case Study in Greece

Table 1: Descriptive statistics of variables

\begin{tabular}{|c|c|c|c|c|c|c|}
\hline ee & & Mean & $\begin{array}{c}\text { Std. } \\
\text { Dev. }\end{array}$ & Maximum & Minimum & Observations \\
\hline AGE & 1.905 & 0.763 & 3.000 & 1.000 & 897 \\
\hline ECONOMY & 1.248 & 0.432 & 2.000 & 1.000 & 897 \\
\hline EDUCA & 7.094 & 1.575 & 9.000 & 1.000 & 897 \\
\hline HEALTHY & 2.509 & 1.051 & 5.000 & 1.000 & 897 \\
\hline MONEY & 3.041 & 0.959 & 5.000 & 1.000 & 897 \\
\hline PHYSICAL & 2.624 & 1.013 & 5.000 & 1.000 & 897 \\
\hline LQS & 0.397 & 0.489 & 1.000 & 0.000 & 897 \\
\hline
\end{tabular}

Regression results are summarized in Table 2. The estimates suggest that there are important links between the sense of quality of life and demographic, social, economic and health characteristics, although the nature of the linkages differs when all characteristics are simultaneously in the model. In columns (a) - (f) of Table 2 the estimated coefficients of all characteristics have a negative sign and are highly significant (1\%), when each one is only separately included in the model. But here we should be careful about the interpretation of the regressors. More specifically, in column (a) the estimated coefficient of ECON has a negative sign, suggesting that more economic autonomy (from value 2 to value 1 ) implies higher probability of LQS. The same interpretations hold in columns (b)-(e). Thus, they imply that greater educational level (from value 9 to value 1), physical energy (from value 5 to value 1 ), health sense (from value 5 to value 1 ) and annual income (from value 5 to value 1 ) lead to higher probability of LQS. But on the other hand, column ( $f$ ) shows that higher AGE (from value 1 to value 3 ) suggest lower probability of LQS. These results are robust with respect to changes in the specification of the regressions by including in several combinations other variables (columns $(\mathrm{g})-(\mathrm{k})$ ). Thus, the coefficients of all regressors are still, at the most cases, highly significant $(1 \%)$ regardless of the inclusion of other variables. But in column (I) our results suggest that the simultaneous inclusion of all regressors, the coefficients of EDUC and AGE have the negative signs but they are insignificant. At the same time, controlling for all variables increases the goodness-of-fit of the regressions and implies that PHYS has the largest impact (estimated coefficient -0.661) on the probability of LQS and the HEALTY has the second one (estimated coefficient -0.224).

Table 2: Sense of Quality of Life and Demographic, Social, Economic and Health Characteristics

\begin{tabular}{|c|c|c|c|c|c|c|c|c|c|c|c|c|}
\hline \multirow[t]{2}{*}{ Explanatory Variables } & \multicolumn{12}{|c|}{ Dependent variable: Sense of quality of life (LQS) } \\
\hline & (a) & (b) & (c) & (d) & (e) & (f) & (g) & (h) & (i) & (j) & (k) & (II) \\
\hline \multirow[t]{2}{*}{ constant } & $0.467^{* * *}$ & $0.999 * * *$ & $1.098^{* * *}$ & $1.776^{* * *}$ & $0.723^{* * *}$ & $0.243^{* * *}$ & $1.467^{* * *}$ & $2.296^{* * *}$ & $3.123^{* * *}$ & $3.202^{* * *}$ & $1.860^{* * *}$ & $3.273^{* * *}$ \\
\hline & $(0.133)$ & $(0.200)$ & $(0.122)$ & $(0.146)$ & $(0.145)$ & $(0.114)$ & $(0.226)$ & $(0.253)$ & $(0.284)$ & $(0.288)$ & $(0.242)$ & $(0.295)$ \\
\hline \multirow[t]{2}{*}{ ECON } & $-0.591^{* * *}$ & & & & & & $-0.499 * * *$ & $-0.432^{* * *}$ & $-0.503^{* * *}$ & ${ }^{*}-0.420^{* * *}$ & $-0.414^{* * *}$ & $-0.445^{* * *}$ \\
\hline & $(0.104)$ & & & & & & $(0.106)$ & $(0.112)$ & $(0.121)$ & $(0.129)$ & $(0.115)$ & $(0.131)$ \\
\hline \multirow[t]{2}{*}{ EDUC } & & $-0.178^{* * *}$ & & & & & $-0.157^{* * *}$ & $-0.109 * * *$ & $-0.076^{* *}$ & $-0.057^{*}$ & $-0.094^{* * *}$ & -0.048 \\
\hline & & $(0.028)$ & & & & & $(0.028)$ & $(0.030)$ & $(0.032)$ & (0.333) & $(0.031)$ & $(0.034)$ \\
\hline \multirow[t]{2}{*}{ HEALTHY } & & & $-0.562^{* * *}$ & & & & & $-0.518^{* * *}$ & $-0.231 * * *$ & ${ }^{*}-0.232^{* * *}$ & & $-0.224^{* * *}$ \\
\hline & & & $(0.048)$ & & & & & $(0.049)$ & $(0.060)$ & $(0.060)$ & & $(0.060)$ \\
\hline \multirow[t]{2}{*}{ PHYS } & & & & $-0.814^{* * *}$ & & & & & $-0.673^{* * *}$ & ${ }^{*}-0.663^{* * *}$ & & $-0.661^{* * *}$ \\
\hline & & & & $(0.057)$ & & & & & $(0.066)$ & $(0.066)$ & & $(0.066)$ \\
\hline \multirow[t]{2}{*}{ FIN } & & & & & $-0.327^{* * *}$ & & & & & $-0.114^{*}$ & $-0.183^{* * *}$ & $-0.109^{*}$ \\
\hline & & & & & $(0.046)$ & & & & & $(0.060)$ & $(0.053)$ & $(0.060)$ \\
\hline \multirow[t]{2}{*}{ AGE } & & & & & & $-0.266^{* * *}$ & & & & & $-0.209^{* * *}$ & -0.077 \\
\hline & & & & & & $(0.056)$ & & & & & $(0.061)$ & $(0.098)$ \\
\hline No. of Observations & 897 & 897 & 897 & 897 & 897 & 897 & 897 & ' 897 & 897 & ' 897 & 897 & 897 \\
\hline McFadden R-squared & 0.028 & 0.035 & 0.129 & 0.215 & 0.042 & 0.019 & 0.054 & 0.157 & 0.255 & 0.258 & 0.075 & 0.259 \\
\hline
\end{tabular}




\subsection{Age Life Quality, Educational Level, Economic Characteristics, and Health Link}

In order to investigate the association of Life Quality Impacts with certain Demographic Characteristics, Social Characteristics, Economic Characteristics and Health Characteristics, the dependent dummy variable was created called Life Quality Sense, consisting of the Medium Term of Variable Quality of Life, Life Enjoyment, and Happiness Sense, mentioned above. The dummy variable was associated with the following variables and groups of variables: The first correlation includes Age variable as Demographic Attribute. The second correlation includes the Educational Level variable as a Social Attribute. The third correlation includes a group consisting of the independent variables Economic Autonomy and Annual Income as Economic Characteristics. The fourth correlation includes a group consisting of the independent variables Physical Energy and Health Sense as Health Characteristics. The results of the linear regression are presented in Table 1, which shows the correlations that have emerged. From the results, the Life Quality Sense (LQS - values 1 to 5), which was created as a dummy variable from the average of Life Quality and Life and Happiness, is related to Age (integer values 1 to 3 ), as a Demographic Characteristic variable, as follows:

LQS $=0,191(\mathrm{AGE})+2,165$

Table 1: Association of Life Quality Sense Elements, Educational Level, Economic Characteristics and Health Characteristics through Linear Regression

\begin{tabular}{|c|c|c|c|c|c|}
\hline Variables & $\begin{array}{l}\text { Dependent False } \\
\text { Variable }\end{array}$ & $\begin{array}{l}\text { Question } \\
\text { number }\end{array}$ & $\begin{array}{l}\text { Independent } \\
\text { Variables }\end{array}$ & $\begin{array}{c}\text { Linear } \\
\text { Regression } \\
\text { Coefficient }\end{array}$ & $\begin{array}{c}\text { Fixed } \\
\text { linear } \\
\text { regression }\end{array}$ \\
\hline $\begin{array}{l}\text { Quality of } \\
\text { life }\end{array}$ & \multirow[b]{2}{*}{$\begin{array}{l}\text { The Sense of } \\
\text { Quality of Life }\end{array}$} & \multicolumn{2}{|c|}{ Demographic Features } & & \\
\hline $\begin{array}{l}\text { Enjoy life } \\
\text { Happy }\end{array}$ & & 2 & Age & $\begin{array}{c}0,191 \\
(p=0,000)\end{array}$ & $\begin{array}{c}2,165 \\
(p=0,000)\end{array}$ \\
\hline $\begin{array}{l}\text { Quality of } \\
\text { life }\end{array}$ & \multirow{2}{*}{$\begin{array}{l}\text { The Sense of } \\
\text { Quality of Life }\end{array}$} & \multicolumn{2}{|c|}{ Social Features } & & \\
\hline Enjoy life & & 9 & $\begin{array}{l}\text { Educational } \\
\text { level }\end{array}$ & $\begin{array}{c}0,103 \\
(p=0,000)\end{array}$ & $\begin{array}{c}1,796 \\
(p=0,000)\end{array}$ \\
\hline $\begin{array}{l}\text { Quality of } \\
\text { life }\end{array}$ & \multirow{3}{*}{$\begin{array}{l}\text { The Sense of } \\
\text { Quality of Life }\end{array}$} & \multicolumn{2}{|c|}{ Financial Features } & & \multirow{3}{*}{$\begin{array}{c}1,663 \\
(p=0,000)\end{array}$} \\
\hline Enjoy life & & 12 & $\begin{array}{l}\text { Economic } \\
\text { self-reliance }\end{array}$ & $\begin{array}{c}0,264 \\
(p=0,000)\end{array}$ & \\
\hline Happy & & 13 & $\begin{array}{l}\text { Annual } \\
\text { income }\end{array}$ & $\begin{array}{c}0,176 \\
(p=0,000)\end{array}$ & \\
\hline $\begin{array}{l}\text { Quality of } \\
\text { life }\end{array}$ & \multirow{3}{*}{$\begin{array}{l}\text { The Sense of } \\
\text { Quality of Life }\end{array}$} & \multicolumn{2}{|c|}{$\begin{array}{c}\text { Characteristics } \\
\text { Health }\end{array}$} & & \\
\hline Enjoy life & & 21 & $\begin{array}{l}\text { I have very } \\
\text { good physical } \\
\text { energy }\end{array}$ & $\begin{array}{c}0,387 \\
(p=0,000)\end{array}$ & \multirow{2}{*}{$\begin{array}{c}1,047 \\
(p=0,000)\end{array}$} \\
\hline Happy & & 15 & $\begin{array}{l}\text { I'm pretty } \\
\text { healthy to } \\
\text { have activity }\end{array}$ & $\begin{array}{c}0,186 \\
(p=0,000)\end{array}$ & \\
\hline
\end{tabular}


It also appears that LQS (values 1 to 5 ) is related to the Educational Level (integer values 1 to 9), as a variable of the Social Characteristics, with the following relationship:

LQS $=0,193$ (Educational Level) $+1,796$

It also appears that LQS ( 1 to 5 values) is related to Economic Autonomy ( 1 to 2 Accuracy) and Annual Income (integer values 1 to 5 ) as variables of Financial Characteristics, with the following relationship:

LQS $=0,264$ (Economic Autnomy) $+0,176$ (Annual Income) $+1,663$

Finally, it appears that LQS (values 1 to 5 ) are related to Physical Energy (1 to 5 ) and Health Sensitivity (1 to 5 ) as Health Characteristics variables with the following relationship:

LQS $=0,387$ (Physical Energy) $+0,186$ (Health Sensitivity) $+1,047$

Of the above, it is obviously more pronounced the proportional relationship of Life Quality Satisfaction with the Health Characteristics of Respondents, the less pronounced or proportional relationship of Life Quality Sense with the Economic Characteristics of Respondents and even less pronounced or proportional relationship of Life Quality Sense with Age the Educational Level, as Demographic and Social Characteristics of Respondents respectively.

The depiction of the economic and social characteristics as well as the state of health of the elderly among the different Centers for Open Elderly Protection of Greece is achieved through the use of the ArcMap program, in which the table data is imported. The figures are plotted in the corresponding geographical locations on the maps, giving the person concerned a full picture of the geographical distribution of economic and social characteristics and, in particular, of the health status of the elderly by region. Thus, the public institutions and health service providers concerned are given the opportunity to take prompt decisions on their actions.

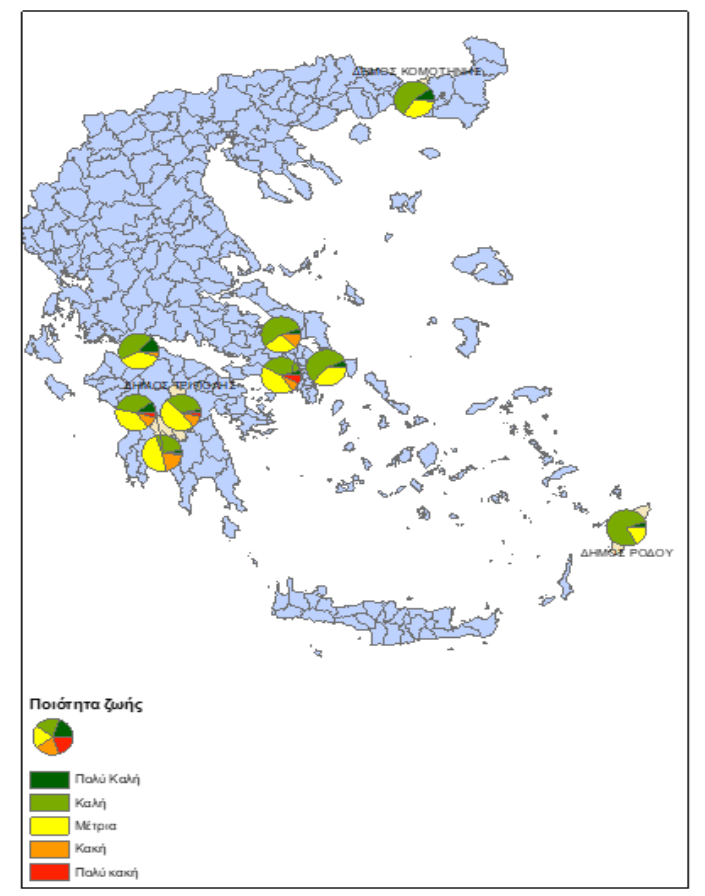




\section{Conclusion}

In this study, we tried to analyze the usefulness of GIS to investigate the socio-economic indicators that affect the health level of the elderly. In particular, the research questions and their relevance, the content of the questionnaire, the data collection process, their processing and analysis, moral ethics, existing constraints, as well as the population and the sample of research were made.

In the statistical survey, the following findings were made regarding the correlation of demographic, social, economic characteristics and health characteristics with aspects of Quality of Life, using the methodology of the Spearrman linear association mentioned above, given that all the associated research variables were mainly qualitative:

1. Regarding the correlation between demographic characteristics and aspects of the Quality of Life of the elderly, it is ascertained that: a) the hypothesis is that the under-70s are better understood and experienced by all aspects of Quality of Life compared to ages 70 80 years old, who in turn live better than those over the age of 80 ; b) there is no statistically acceptable relationship between the marital status and the aspects of Quality of Life.

2. Regarding the correlation between social characteristics and aspects of the quality of life of the elderly, it is established that: a) the hypothesis is that residents living in urban areas today perceive and better live all aspects of Quality of Life compared to those residing in semi-subsistence areas which, in turn, live better than those living in rural areas; (b) the hypothesis is verified that those living in urban areas in the past and better live all aspects of Quality of Life compared to those living in semi-urban areas, which in turn live better than those living in rural areas; (c) the hypothesis is verified that holders of higher education qualifications and better live through all aspects of Quality of Life compared to those with lower education qualifications.

3. Regarding the existence of correlations between the economic characteristics and the aspects of the Quality of Life of the elderly, it is established that: a) the hypothesis is verified that those with economic self-sufficiency better live all aspects of Quality of Life compared to those lacking economic self-sufficiency; ) the hypothesis is verified that those with the highest annual income better understand and live all aspects of Quality of Life compared to those that have a lower level; c) the hypothesis is verified that those who believe that the economic crisis does not affect them, they perceive better the Quality of Life and they are of the opinion that they enjoy life. However, the perception of the current economic crisis is not statistically correlated with a sense of happiness for most of the time.

4. Regarding the existence of correlations between health attributes with the aspects of Quality of Life of the elderly, it is established that: a) the hypothesis is verified that the health-enabling person of the activity best suits all aspects of Quality of Life compared to those who do not (b) the hypothesis is established that those who have a good physical condition better live all aspects of Quality of Life than those who do not have a good physical condition; (c) verifiability it is assumed that those suffering from pain affecting their well-being have a worse outreach to all aspects of Quality of Life than those who do not suffer from pain; (d) the hypothesis is confirmed that those who have a problematic health that confines them to home live worse all aspects of Quality of Life compared to those not limited to home for health reasons.

The figures are plotted in the corresponding geographical locations on the maps, giving the person concerned a full picture of the geographical distribution of economic and social characteristics and, in particular, of the health status of the elderly by region. 


\section{References}

- Adler, N., Ostrove, J. (1999). "Socioeconomic Status and Health: What We Know and What We Don't", Annals of the New York Academy of Sciences 896:3-15. Crossref

- Andrulis, D.P. (1998). "Access to Care Is the Centerpiece in the Elimination of Socioeconomic Disparities in Health", Annals of Internal Medicine 129:412-416. Crossref

- Caraher, M., Dixon, P., Lang, T., Carr-Hill, R. (1998). "Access to Healthy Foods: Part I. Barriers to Accessing Healthy Foods: Differentials by Gender, Social Class, Income and Mode of Transport", Health Education Journal 57:191-201Crossref

- Cohen, D.A., Thomas A.F., Karen, M. (2003). "Why Is Poverty Unhealthy? Social and Physical Mediators", Source Social Science \& Medicine 57:1631-1641. Crossref

- Darmon, N., Ferguson, E.L., Briend, A. (2002). "A Cost Constraint Alone Has Adverse Effects on Food Selection and Nutrient Density: An Analysis of Human Diets by Linear Programming", The Journal of Nutrition 132:3764-3771. Crossref

- Evans, G.W., Katrowitz, E. (2002). "Socioeconomic Status and Health: the Potential Role of Environmental Risk Exposure", Annual Review of Public Health 23:303-331Crossref

- Ezatti, M., Utzinger J., Cairncross, S., Cohen, A.J., Singer B.H. (2005). "Environmental risks in the developing world: exposure indicators for evaluating interventions, programmes and policies", Journal of Epidemiology and Community Health, (59):15-22. Crossref

- Feinstein, J.S. (1993). "The Relationship Between Socioeconomic Status and Health." Milbank Quarterly 71:279-322. Crossref

- Foley, R. (2002). "Assessing the applicability of GIS in a health and social care setting: planning services for informal carers in East Sussex, England", Social Science \& Medicine, 55:79-96. Crossref

- Goldman, D., Smith, J.P. (2002). "Can Patient Self-Management Help Explain the SES Health Gradient?", Proceedings of the National Academy of Sciences of the United States of America 99: 109-129. Crossref

- Hanchette, C.L. (2003). "Geographic Information Systems", in O'Carroll, P.W., Yasnoff, Y.A., Ward, M.E., Ripp, L.H., Martin, E.L. (Ed.), Public Health Informatics (pp. 431-466). New York, NY: Springer. Crossref

- Hayward, R.A., Shapiro, M.F., Freeman, H.E., Corey, Ch.R. (1988). "Who Gets Screened for Cervical and Breast Cancer? Results from a New National Survey", Archives of Internal Medicine 148:1177-1181. Crossref

- Herd, P., Goesling, B., House, J.S. (2007). "Socioeconomic Position and Health: The Differential Effects of Education versus Income on the Onset versus Progression of Health Problems", Journal of Health and Social Behavior 48:223-238. Crossref

- House, J.S. (2002). "Understanding Social Factors and Inequalities in Health: 20th Century Progress and 21st Century Prospects", Journal of Health and Social Behavior 43:125-142. Crossref

- Kitagawa, E.M., Hauser, P.M. (1973). Differential mortality in the United States: a study in socioeconomic epidemiology, Cambridge, MA: Harvard University Press.

- Kitagawa, E.M., Hauser, P.M. (1973). Differential mortality in the United States: a study in socioeconomic epidemiology, Cambridge, MA: Harvard University Press.

- Lantz, P.M., House, J.S., Mero, R.P., Williams, D.R. (2005). "Stress, life events, and socioeconomic disparities in health: results from the Americans' Changing Lives Study", J. Health Soc. Behav., 46:274-288. Crossref

- Lantz, P.M., House, J.S., Mero, R.P., Williams, D.R. (2005). "Stress, life events, and socioeconomic disparities in health: results from the Americans' Changing Lives Study", J. Health Soc. Behav., 46:274-288. Crossref

- Lin, N., Ensel. W.M., (1989). "Life Stress and Health: Stressors and Resources." American Sociological Review 54:382-399 Crossref 
- Lowry, D., Xie Y. (2009). "Socioeconomic Status and Health Differentials in China: Convergence Or Divergence at Older Ages?", Population Studies Center Research Report 09-690. October 2009.

- Makuc, D., Feldman, J.J., Kleinman, J.C., et al. (1990). "Sociodemographic differentials in mortality" in: Cornoni-Huntley, J.C., Huntley, R.R., Feldman, J.J., eds. Health status and well-being of the elderly: National Health and Nutrition Examination Survey-I Epidemiologic Follow-up Study, New York, NY: Oxford University Press, 155-71.

- Marmot, M., Ryff, C.D., Bumpass, L.L., Shipley, M., Marks, N.F. (1997). "Social Inequalities in Health: Next Questions and Converging Evidence", Social Science and Medicine 44:901910. Crossref

- Mirowsky Link, B.G., Phelan, J. (1995). "Social Conditions as Fundamental Causes of Disease", Journal of Health and Social Behavior 35:80-94. Crossref

- Mirowsky, J., Ross, C.E. (1998). "Education, Personal Control, Lifestyle and Health: A Human Capital Hypothesis", Research on Aging 20:415-449 Crossref

- Mirowsky, J., Ross, C.E. (1999). "Economic Hardship across the Life Course", American Sociological Review 64:548-569 Crossref

- Najafabadi, AT. (2009). "Applications of GIS in Health Sciences", Shiraz E-Medical Journal; 10(4):221-230.

- Rosenbaum, E. (2008). "Racial/Ethnic Differences in Asthma Prevalence: The Role of Housing and Neighborhood Environment", Journal of Health and Social Behavior 49:131145. Crossref

- Ross, C.E., Chia-Ling Wu. (1995). "The Link Between Education and Health", American Sociological Review 60, 719-745. Crossref

- Taylor, Sh.E., Seeman, T.E. (1999). "Psychosocial Resources and the SES-Health Relationship", Annals of the New York Academy of Sciences 896:210-225.

- von dem Knesebeck, O., Verde, P.E., Dragano, N. (2006). "Education and Health in 22 European Countries", Social Science \& Medicine 63:1344-1351. Crossref

- Yasnoff, W.A., Miller, P.L. (2003). "Decision Support and Expert Systems in Public Health", in O'Carroll, P.W., Yasnoff, Y.A., Ward, M.E., Ripp, L.H., Martin, E.L. (Ed.), Public Health Informatics (pp. 494-512). New York, NY: Springer. Crossref

- Zimmer, Z., House, J.S. (2003). "Education, Income, and Functional Limitation Transitions among American Adults: Contrasting Onset and Progression" International Journal of Epidemiology 32:1089-1097. Crossref

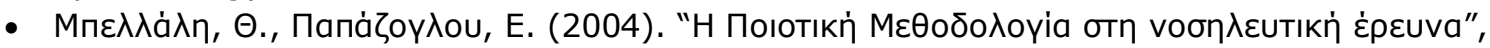

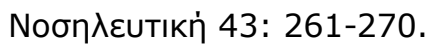

